\title{
Effect of the Mix Size of Amalgam on the Triturating Time
}

\author{
by \\ Kazuo NAGAI,* Masayoshi OHASHI,* Hiroyoshi HABU,* \\ Kojiro MAKINO,* Tadashi USUI,* Motoyuki MATSUO,* \\ Mitsuhiro HAMA* and Morio KAWAMOTO*
}

\section{Introduction}

It is generally held that a larger mix size of amalgam tends to require a correspondingly longer time for an adequate trituration. In a widely used textbook on the subject[1], it is given that, when 12 grain amalgam is to be reduced to 6 grain by mechanical trituration, the triturating time will have to be reduced by about 3 seconds; on the other hand, when a larger size is to be used, the time will be prolonged by 3 to 5 seconds than what is considered standard.

The instruction accompanying an amalgamator usually states that a longer triturating time should be used for a large size of mix. While accepting the above statement, we wonder if an undermix will result when a shorter triturating time is used for a small size of mix. Complaints are often heard from the clinician that, when a size of mix is too small, it is very difficult to obtain amalgam mix of homogenous plasticity.

In the present study, the authors were concerned with a comparative analysis of different amalgamators and different alloys with a chief emphasis on the effect of mix size on a triturating time. As a criterion for triturating effect, use was made of the point of sound-change as advanced by PHILLIPs[2]. This concept is much easier than in terms of other physical properties $[3,4,5,6]$ and it is more accurate than the subjective experience on the part of an operator[7]. The point of sound-change is sometimes more efficient than a timer attached to the amalgamator[2]. Preliminary tests established the fact that, when an amalgamator was stopped at the point when soundchange occurred, amalgam mix of the homegenous plasticity could be always obtained. Transparent capsules of plastic tube were manufactured and the same findings were visually confirmed.

\section{Materials and Method}

By way of experimental materials, Shofu Spherical Alloy (Batch No. 217) and Shofu Micro Alloy (Batch No. 43), both products of Shofu Dental Mfg. Co., Kyoto, were selectively used. These are to be abbreviated as SS8 and SM respectively.

What we called the size 1 (one) of mix consisted of $0.35 \mathrm{~g}$ (spherical) and $0.30 \mathrm{~g}$

*永井一夫, 大橋正敬, 土生博義, 牧野浩次郎, 臼井規, 松尾基幸, 浜光洋, 川本盛夫 Dept. of Dental Materials, Nihon Univ. School of Dentistry, Tokyo 
(lathe-cut conventional amalgam) each. A mercury-alloy ratio for SS8 was. 0.85, while that for SM was 1.0. The amount was in 4 arithmetic progressions from size 1 to size 4. Six amalgamators used were: $i$. Shofu Mixer (Shofu Dental Mfg. Co.), ii. G-C Amalgamtor Luna IIB (G-C Chemical Co.), iii. Toothmaster (Toothmaster Co., USA), $i v$. Wig-L-Bug (Crescent Dental Mfg. Co., USA), v. S.S. White 3A (S.S. White Dental Mfg. Co., USA) and vi. Silamat (Vivadent, Lichten Stein). Torit was originally included but, because of a large rotary noise, it was rejected as being unsuitable for measurement purposes. SS8 was used without pestles, whereas SM was used conjointly with pestle or metallic ball. Since Silamat has no pestle, G-C capsule and ball were used with it.

With SS8, various capsules were tried on Silamat (an amalgamator with a good triturating efficiency and a little noise) and Toothmaster (an amalgamator with the average efficiency) for a comparison. Transparent capsules of plastic were manufactured in different sizes; 24, 26, 28 and 30mm in length and 6,8 and $10 \mathrm{~mm}$ in diameter. SS8 'was mixed by the above two amalgamators in combination with these capsules.

The use of a stopwatch seems to be sufficient for the measurement of points of sound-change but, here, a microphone was used to insure an accuracy. Variations in sound were recorded on the oscillograph. Fig. 1 gives a part of chart recorded.

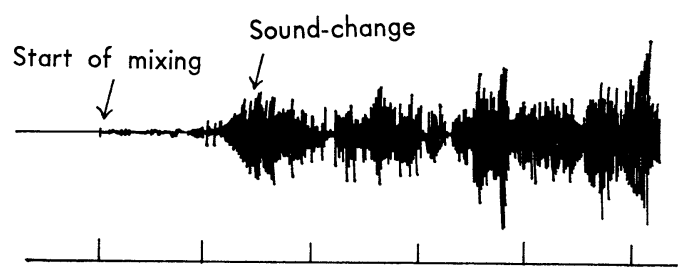

Fig. 1 Recording of sound-change.

\section{Findings}

\subsection{Various amalgamators compared.}

As given in Tables 1 and 2, the rotary speed, movement distance of capsules, movement trend and material and dimension of capsules of 6 amalgamators were investigated and compared. A storoboscopic apparatus was used for the measurement of rotary speed and movement distance of the amalgamators.

Our data appear to be somewhat different from those given by EAMEs[5], which fact may be attributed to the difference of voltage or among the respective amalgamators used.

As for revolutions, Silamat is found to be the fastest (3600 rpm), G-C, Shofu, Toothmaster and Wig-L-Bug are within a range of 2700 to $3000 \mathrm{rpm}$. S.S. White is the slowest in this respect $(1440 \mathrm{rpm})$. In terms of the movement distance of capsules, G-C is the longest $(28 \mathrm{~mm})$ and Silamat is the second $(23 \mathrm{~mm})$. Shofu, Toothmaster and Wig-L-Bug are found within a range of 16 to $17 \mathrm{~mm}$. As for materials of which these 
capsules are made, Shofu, Toothmaster and Silamat use soft plastic, G-C is made of bakelite, S.S. White is of hard plastic and Torit is made of metal. Wig-L-Bug uses a combination of bakelite and metal.

Distribution of the points in sound-change of SS8 mixed by these amalgamators appears in Table 3 and Fig. 2.

TABLE 1

Speed, Capsule Thrust Distance and Type of Capsule Movement of Amalgamators

\begin{tabular}{lccc}
\hline Amalgamator & $\begin{array}{l}\text { Speed } \\
(\text { RPM })\end{array}$ & $\begin{array}{l}\text { Capsule thrust } \\
\text { distance }(\mathrm{mm})\end{array}$ & $\begin{array}{l}\text { Type of capsule } \\
\text { movement }\end{array}$ \\
\hline Shofu & 2880 & 16 & Straight horizontal \\
G-C & 3000 & 28 & Figure eight \\
Toothmaster & 2880 & 16 &,$"$, \\
Wig-L-Bug & 2700 & 17 &, \\
Silamat & 3600 & 23 & Eccentric \\
S.S. White & 1440 & - &
\end{tabular}

TABLE 2

Material, Size and Type of Capsules

\begin{tabular}{llccc}
\hline \hline Capsule & Material & $\begin{array}{c}\text { Length } \\
(\mathrm{mm})\end{array}$ & $\begin{array}{c}\text { Inside } \\
\text { diameter } \\
(\mathrm{mm})\end{array}$ & $\begin{array}{c}\text { Type } \\
\text { (shape of ends) }\end{array}$ \\
\hline Shofu & Soft plastic & 19 & 10 & Flat \\
G-C & Bakelite & 24 & 9 & Round \\
Toothmaster & Soft plastic & 29 & 10 & ", \\
Wig-L-Bug & Bakelite & 24 & 9 & , \\
Wig-L-Bug & Metal & 29 & 7 & " \\
Silicap* & Soft plastic & 29 & 9 & Flat \\
S.S. White & Plastic & 26 & 9 & \\
Torit & Metal & 24 & 9 &
\end{tabular}

TABLE 3

Time of Sound-change of Spherical Alloy Amalgam mixed by Various Amalgamators

\begin{tabular}{lrrrr}
\hline \multirow{2}{*}{ Amalgamator } & \multicolumn{4}{c}{ Size of mix } \\
& 1 & 2 & \multicolumn{3}{c}{3} \\
\cline { 2 - 4 } & \multicolumn{4}{c}{ Time of sound-change (sec.) } \\
\hline Shofu & 2.7 & 2.3 & 1.5 & 1.2 \\
G-C & 1.6 & 1.0 & 0.8 & 0.4 \\
Toothmaster & 18.7 & 16.5 & 13.6 & 13.2 \\
Wig-L-Bug1) & 18.0 & 16.2 & 14.9 & 13.0 \\
Silamat & 2.3 & 2.1 & 0.8 & 0.7 \\
S.S. White & 2.9 & 2.6 & 2.6 & 2.7 \\
& 1)With bakelite capsule & &
\end{tabular}




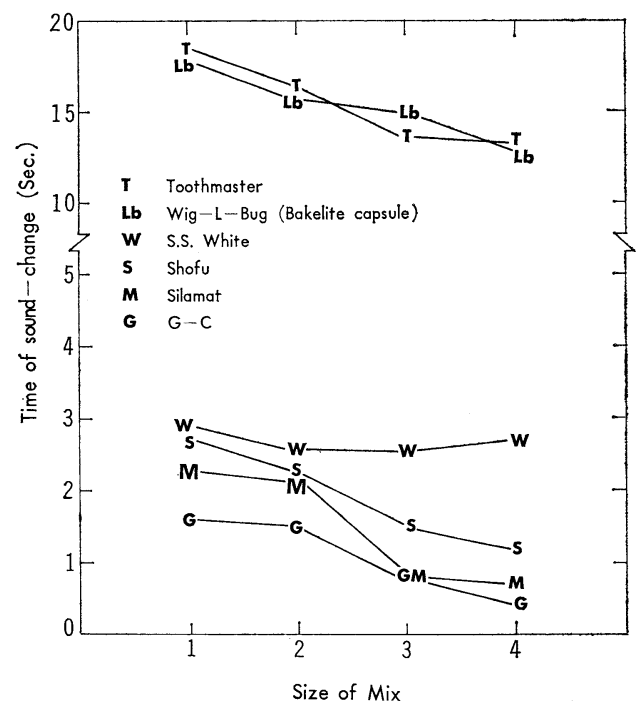

Fig. 2 Time of Sound-change of Spherical Alloy Amalgam mixed by Various Amlgamators

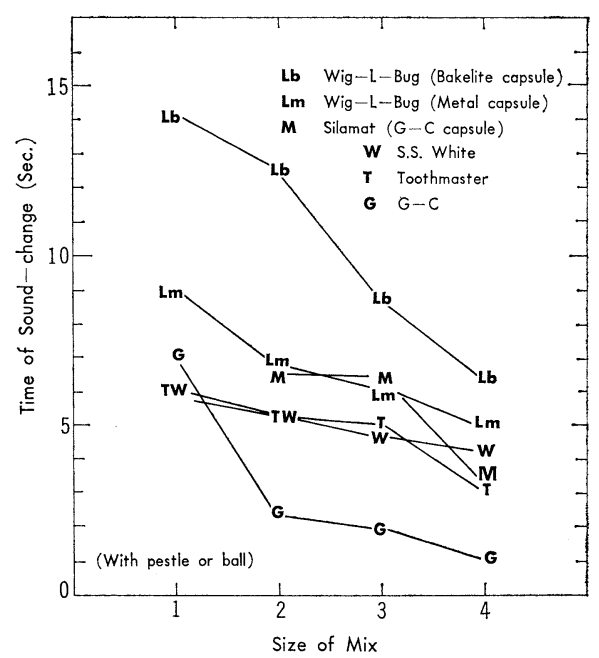

Fig. 3 Time of Sound-change of Conventional Alloy Amalgam mixed by Various Amalgamators

As can be determined from these, the general outcome is that the larger a mix is, the sooner it can be triturated with a single exception of S.S. White, which amalgamates with the more or less the same length of triturating time hardly influenced by the size 
TABLE 4

Time of Souno-change of Conventional Alloy Amalgam mixed by Various Amalgamators

\begin{tabular}{|c|c|c|c|c|}
\hline \multirow{3}{*}{ Amalgamator } & \multicolumn{4}{|c|}{ Size of mix } \\
\hline & 1 & 2 & 3 & 4 \\
\hline & \multicolumn{4}{|c|}{ Time of sound-change (sec.) } \\
\hline G-C & 7.1 & 2.3 & 2.0 & 1.0 \\
\hline Toothmaster & 6.1 & 5.3 & 5.1 & 3.1 \\
\hline Wig-L-Bug1) & 14.2 & 12.6 & 8.7 & 6.4 \\
\hline Wig-L-Bug') & 9.1 & 6.7 & 6.1 & 6.0 \\
\hline Silamat $^{3)}$ & - & 6.5 & 6.3 & 3.5 \\
\hline S.S. Whitd & 6.0 & 5.4 & 4.7 & 4.3 \\
\hline
\end{tabular}

of a mix. Sound-change takes place in the order of G-C, Silamat, Shofu and S.S. White. Toothmaster and Wig-L-Bug (plastic capsule) register a sound-change in 18 seconds with the size 1 and in 13 seconds with the size 4 .

SM is compared in Table 4 and Fig. 3. The occurrence of sound-change gives the same pattern as in SS8. Wig-L-Bug, which requires the longest time, registers a soundchange with the size 4 in $1 / 2$ of what is required for the size 1 . When a bakelite capsule is changed for a metal one, a sound-change will take place sooner. Toothmaster registers a sound-change sooner when spherical amalgam is used.

\subsection{Effects of conjoined capsules.}

Various capsules were tried with Silamat (Table 5, Fig. 4). Shofu capsule did not fit it because of a special shape and the metal capsule for Wig-L-Bug proved unsuitable for the measurement.

Here, as in 3.1 above, the general finding was that a larger mix registered a correspondingly early sound-change. With S.S. White, a sound-change took place latest when the size 1 was used, curves of which being quite steep. Results with Toothmaster are compared in Table 6, Fig. 5. Wig-L-Bug had a capsule-holder quite unfit

TABLE 5

Time of Sound-change of Spherical Alloy Amalgam mixed by Silamat with Various Capsules

\begin{tabular}{lcccc}
\hline \hline \multirow{2}{*}{ Capsule } & \multicolumn{3}{c}{ Size of mix } \\
& 1 & 2 & 3 & 4 \\
\cline { 2 - 4 } & \multicolumn{4}{c}{ Time of sound-change (sec.) } \\
\hline G-C & 2.6 & 2.4 & 1.1 & 0.8 \\
Toothmaster & 3.0 & 2.4 & 1.8 & 0.6 \\
Wig-L-Bug') & 1.5 & 1.5 & 1.4 & 1.1 \\
Silicap & 2.3 & 2.1 & 0.8 & 0.7 \\
S.S. White & 4.0 & 2.1 & 1.7 & 1.5 \\
Torit & 1.9 & 1.4 & 1.2 & 0.6 \\
& & & &
\end{tabular}


for that of Toothmaster and was rejected from the measurement for this reason. When mixed by Toothmaster, the relationship between the size of mix and point of soundchange was constant. However, when contrasted with Silamat, Toothmaster registers a sound-change somewhat later and order of curves is different. With Torit, soundchange failed to occur in the size 1 even after 30 seconds: a close scrutiny revealed the mix to be a conglomeration of small particles, $2 \sim 3 \mathrm{~mm}$ in size, and the mix did not become one mass.

TABLE 6

Time of Sound-change of Spherical Alloy Amalgam mixed by Toothmaster with Various Capsules

\begin{tabular}{lccrr}
\hline \multirow{2}{*}{ Capsule } & \multicolumn{4}{c}{ Size of mix } \\
& 1 & 2 & 3 & 4 \\
\cline { 2 - 4 } & \multicolumn{4}{c}{ Time of sound-change (sec.) } \\
\hline G-C & 12.8 & 6.9 & 3.9 & 3.7 \\
Toothmaster & 18.7 & 16.5 & 13.6 & 13.2 \\
Silicap & 12.4 & 10.0 & 8.1 & 5.2 \\
S.S. White & 12.6 & 11.8 & 11.6 & 8.6 \\
Torit & - & 22.1 & 15.6 & 12.6
\end{tabular}

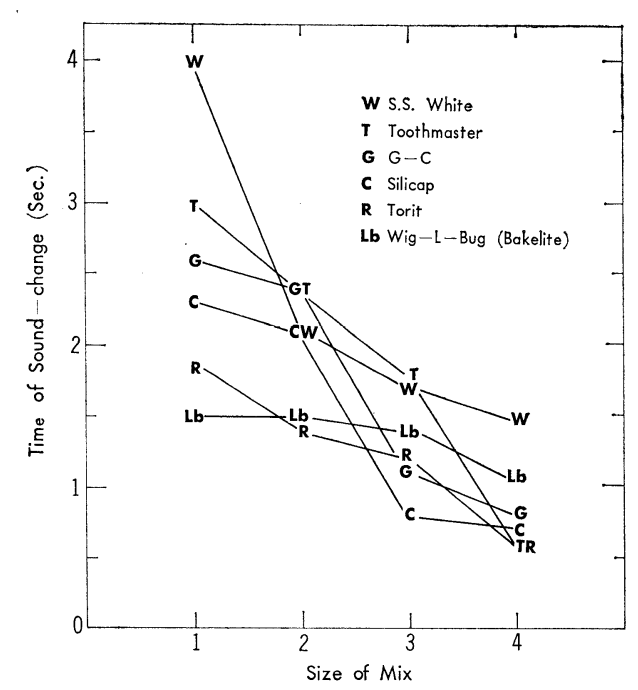

Fig. 4 Time of Sound-change of Spherical Alloy Amalgam mixed by Silamat with Various Capsules 


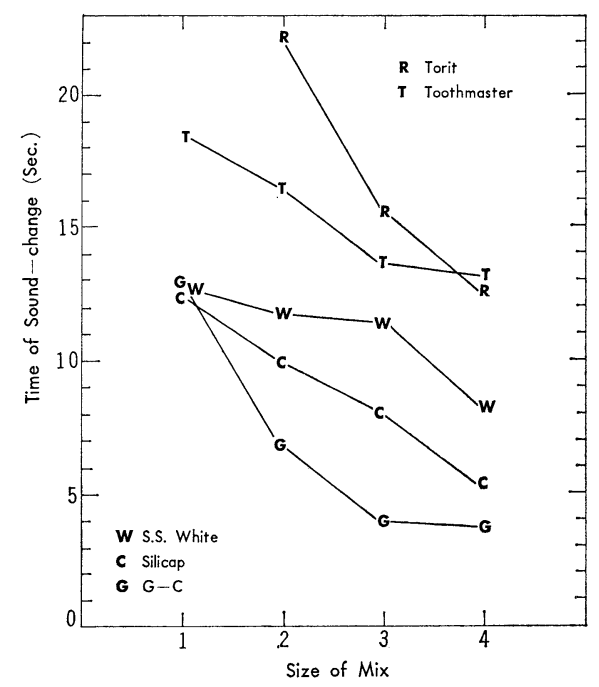

Fig. 5 Time of Sound-change of Spherical Alloy Amalgam mixed by Toothmaster with Various Capsules

\subsection{Change in the inner dimension of capsules.}

Spherical amalgam (SS8) was mixed by Silamat and Toothmaster with each of the capsules prepared (Tables 7 and 8).

With Silamat, the occurrence of sound-change becomes suddenly delayed when the capsule exceeds $30 \mathrm{~mm}$ in length, thus affecting the size of mix. With Toothmaster, on the other hand, the trituration is insufficient except for the size 4: in other cases, it failed to form one solid mass.

TABLE 7

Time of Sound-change of Spherical Alloy Amalgam mixed by Silamat with Different Size Capsules

\begin{tabular}{cccccc}
\hline $\begin{array}{l}\text { Inside length } \\
\text { of capsule }(\mathrm{mm})\end{array}$ & $\begin{array}{c}\text { Inside diameter } \\
\text { of capsule }(\mathrm{mm})\end{array}$ & 1 & \multicolumn{3}{c}{ Size of mix } \\
\hline & & \multicolumn{4}{c}{ Time of sound-change (Sec.) } \\
\hline \multirow{2}{*}{24} & 6 & 0.8 & 0.8 & 0.6 & 0.6 \\
& 8 & 0.7 & 0.6 & 0.6 & 0.5 \\
& 10 & 0.5 & 0.5 & 0.5 & 0.4 \\
26 & 6 & 0.7 & 0.7 & 0.7 & 0.6 \\
& 8 & 0.9 & 0.7 & 0.6 & 0.5 \\
& 10 & 0.5 & 0.4 & 0.4 & 0.4 \\
& 6 & 0.8 & 0.7 & 0.6 & 0.5 \\
& 8 & 0.7 & 0.6 & 0.6 & 0.6 \\
& 10 & 0.6 & 0.4 & 0.5 & 0.4 \\
& 6 & 1.6 & 0.8 & 0.7 & 0.6 \\
& 6 & 1.8 & 1.0 & 0.8 & 0.7 \\
& 10 & 3.2 & 2.3 & 1.9 & 0.9
\end{tabular}


TABLE 8

Time of Sound-change of Spherical Alloy Amalgam mixed by Toothmaster with Different Length Capsules (10 $\mathrm{mm}$ inside diameter)

\begin{tabular}{|c|c|c|c|c|}
\hline \multirow{2}{*}{$\begin{array}{l}\text { Inside length of } \\
\text { capsule (mm) }\end{array}$} & \multicolumn{4}{|c|}{ Size of mix } \\
\hline & 1 & 2 & 3 & 4 \\
\hline & \multicolumn{4}{|c|}{ Time of sound-change (sec.) } \\
\hline 24 & * & 15.0 & 14.8 & 10.4 \\
\hline 26 & * & $*$ & 22.0 & 14.2 \\
\hline 28 & $*$ & $*$ & $*$ & 20.6 \\
\hline 30 & $*$ & $*$ & $*$ & 21.4 \\
\hline
\end{tabular}

\subsection{Observations of amalgam mix through the transparent capsule.}

Capsules were manufactured of transparent plastic tube, $10 \mathrm{~mm}$ in inner diameter and $30 \mathrm{~mm}$ in inner length. SS8 was amalgamated by Silamat for 1 to 20 seconds and the mix was placed inside the tube for direct observations. In the figures to follow, results are based on 1 to 5 seconds trituration and numerals in the figures indicate the size of mix used.

As is given in Fig. 6, when the mix is observed after one second triburation, the size 1 is hardly amalgamated. The size 2 is still in the state of powder, the size 3 becomes round in shape but it lacks lustre and full of minute cracks. The size 4 becomes completely round and begins to assume a certain measure of lustre.

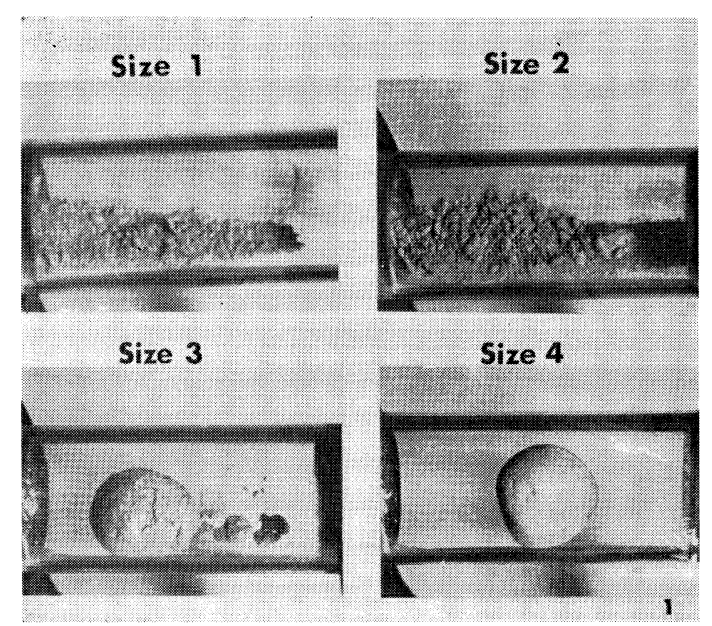

Fig. 6 1-second mixing 
Time-wise changes from the size 1 to 4 can be tabulated as follows.

\begin{tabular}{ccl} 
Size & Round in shape & \multicolumn{1}{c}{ Lustre } \\
\hline 1 & 5 sec. trit. & Imperfect, no lustre \\
2 & 3 sec. & 4 sec. \\
3 & 2 sec. & 2 sec. \\
4 & 1 sec. & 1 sec.
\end{tabular}

These findings definitely support an empirical thinking that a large amount can be mixed with a correspondingly short time.

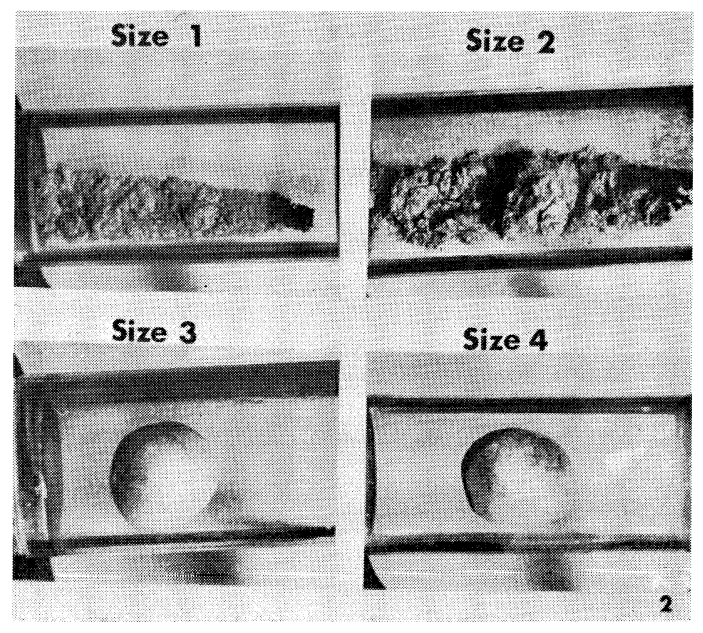

Fig. 7 2-second mixing

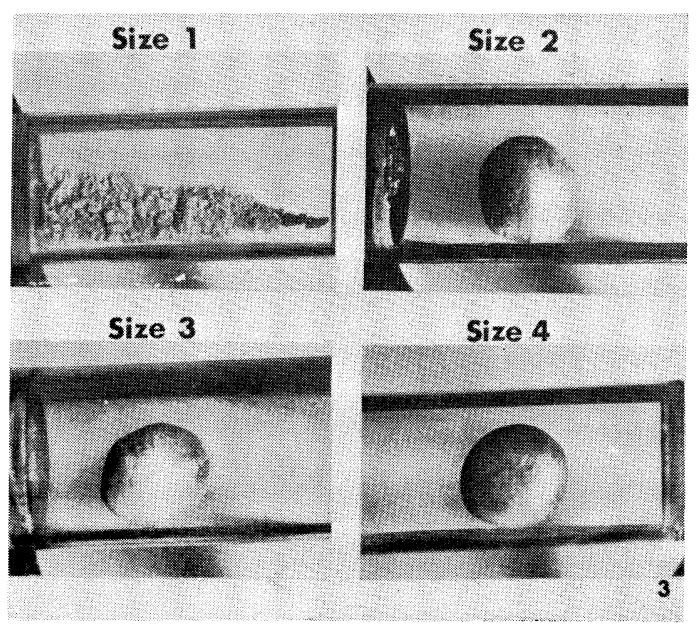

Fig. 8 3-second mixing 


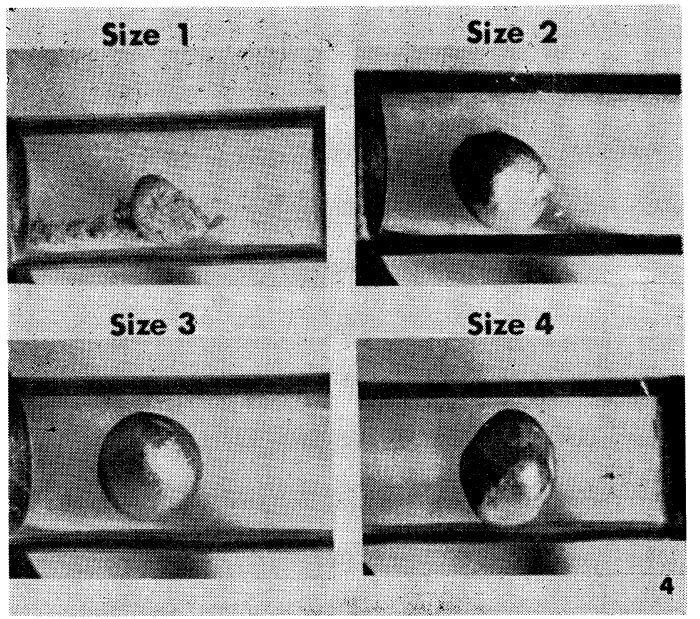

Fig. 9 4-second mixing

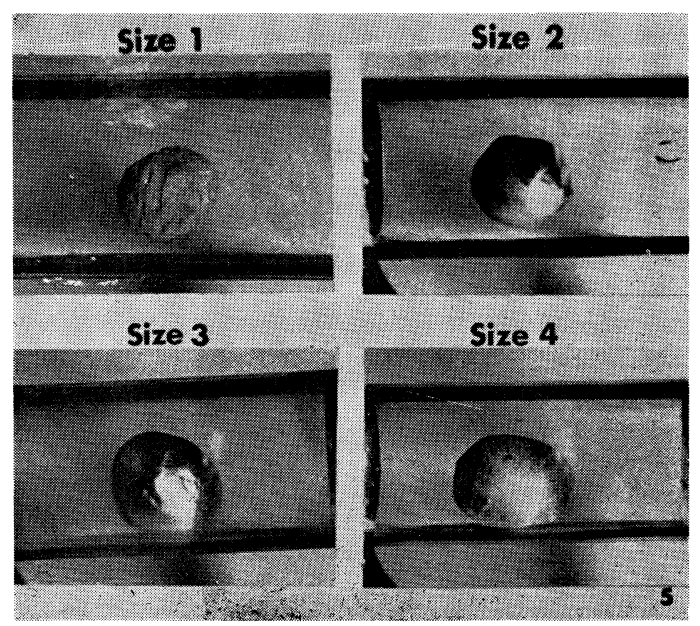

Fig. $10 \quad$ 5-second mixing

\section{Discussion}

\subsection{Evaluation of triturating effect by sound-change.}

An optimal time for amalgamation varies depending on the type of amalgam alloy product, amalgamator to be used and so forth. Under clinical environment, it is impractical to determine triturating effect by physical properties at each amalgamation. For this reason, the application of sound-change has much clinical service to perform: in particular, powder type spherical amalgam lends itself readily to this concept because it does not necessitate the use of pestle. Our experimental findings reveal 
that time at which alloy and mercury form ball is to be set a little after the occurrence of sound-change, an optimal trituration and sound-change not being synonymous. Our concern in the present investigation has been with an evaluation of triturating effect by applying the concept of sound-change.

\subsection{Effect due to different mix sizes.}

It has been generally agreed that a large size of mix calls for a long trituration time. But, as far as our own findings based on 12 kinds of amalgam go, the occurrence of sound-change takes place sooner when a large mix is triturated. These findings are in direct opposition to the previously held view; however, we are not in a position to maintain that a short triturating time will always suffice for a small size of mix. For such factors need to be taken into account as a large mix receives less influence, a good amalgamator registers sound-change with a little margin of 2 or 3 seconds regardless of a size of mix, and an optimal trituration is not equated with the point of soundchange. At the same time, it must be borne in mind that, when a size of mix happens to be very small, there is a possibility of its being undermixed. If indicated, a triturating time should be prolonged rather than shortened.

When a large size of mix is used, a ratio of the capsule volume to the content will become the greater, a movement energy increasing proportionally to the content mass. As the revolution speed of an amalgamator or movement distance of capsules has no appreciable effect on the size of mix[4], amalgam mud at amalgamation receives a correspondingly large pressure and thus results in a quicker trituration. From the same theoretical consideration, EAMES [5] recommends the use of heavy pestle.

The possibility of a small mix size being undermixed has an important clinical meaning. Physical properties of amalgam mixed with various sizes will receive our future research efforts.

\subsection{Evaluation of various amalgamators.}

The number of revolutions of an amalgamator, movement distance of capsules, their dimension and material are all important factors which come into amalgamation.

These considerations definitely manifest themselves in G-C and Silamat which have more revolutions and longer movement distance of capsules. On the other hand, Wig-L-Bug and Toothmaster, which have 2700 to 2900 revolutions almost twice as those of S.S. White, register much delayed sound-change. When examined in terms of compressive and tensile strength[4, 5, 6], these two amalgamators cannot be said to be efficient ones, which is also endorsed by the present findings. The chief drawback of these amalgamators may be sought in the short capsule movement. With Toothmaster, some of energy might be lost through the up-and-down movement of capsule.

Materials for the capsule will have to be considered from the generation of heat through the friction, emission of heat, etc.

\subsection{Effect of inner dimension of capsules.}

When amalgamated by Silamat, the resultant mix received less influence when the inner length of capsule was $24-28 \mathrm{~mm}$. However, when the inner length exceeded $30 \mathrm{~mm}$, influence became quite pronounced. The general trend was that sound-change 
was delayed proportionally to an increase in the inner length. This was true of Toothmaster. That is, when an inner volume of capsule is too large out of proportion of an amount to be mixed, energy within the same distance tends to be lost, hence a longer trituration.

Although influenced by the kind of amalgamators or amalgam, the inner length of capsule is ideally less than $30 \mathrm{~mm}$.

\subsection{Direct observation of amalgam mix.}

The result of direct observations of the amalgam mix placed inside a transparent plastic capsule reveals that a large size of mix will be amalgamated with a correspondingly short time, as in the case of sound-change.

An operator can freely observe time-wise change in the mix by the use of this kind of transparent capsule. The use of transparent capsule is recommended for an operator to determine his own triturating time, conjointly with the application of sound-change, for his brand of amalgam and the amalgamator which he habitually employs.

\section{Conclusions}

1. In mechanical amalgamation, sound-change takes place at a certain stage of time passage. This point of sound-change is indicative of the fact that mercury and alloy have become thoroughly mixed and formed themselves into globes.

2. The point of sound-change is considered to be related to an optimal triturating time, though not synonymous. It should prove a useful guide to the clinician.

3. Sound-change takes place proportionally to the size of mix. In other words, the larger size to be mixed the sooner appears sound-change.

4. Such factors as the revolutions or speed of an amalgamator, movement distance and inner length of capsules definitely enter into the triturating effect of amalgam.

5. The use of transparent plastic capsule can be recommended for direct observations of amalgam mix in process of amalgamation.

\section{References}

[1] Peyton, F.A.: Restorative dental materials, The C.V. Mosby Co., 3rd ed., 1968.

[2] Phillips, R.W.: Physical properties of amalgam as influenced by the mechanical amalgamator and peneutic condenser, J.A.D.A., 31: 1308, 1944.

[3] Overbarger, J.E. and others: The effect of mechanical amalgamation on the strength of amalgam, J.D. Res., 43: 263, 1964.

[4] Osborne, J.W. and others: Compressive strength of amalgam triturated by a high-speed amalgamator and by a ultrahigh-speed mixer, J. Pros. Dent., 19: 598, 1968.

[5] Eames, W.B.: An evaluation of nine amalgamators, J.A.D.A., 78: 1320, 1969.

[6] Shimizu, T.: Study on the optimum trituration time and ability of various amalgamators, J.D.M.A., $21:$ 80, 1970.

[7] Markeley, M.R.: Restorations of silver amalgam, J.A.D.A., 43: 133, 1951. 